\title{
Evaluation of outcome following paracervical infiltration with or without saline and adrenaline during vaginal hysterectomy
}

\author{
Jayaraman Nambiar M.*, Bhaygarekha Yettinamani, Muralidhar V. Pai
}

Department of Obstetrics and Gynecology, Kasturba Medical College, Manipal, India

Received: 24 February 2017

Accepted: 27 March 2017

\section{*Correspondence:}

Dr. Jayaraman Nambiar M.,

E-mail: drramnambiar@gmail.com

Copyright: () the author(s), publisher and licensee Medip Academy. This is an open-access article distributed under the terms of the Creative Commons Attribution Non-Commercial License, which permits unrestricted non-commercial use, distribution, and reproduction in any medium, provided the original work is properly cited.

\section{ABSTRACT}

Background: Paracervical infiltration is used in vaginal hysterectomy to facilitate dissection. Use of paracervical infiltration however can be associated with local ischemia and infection. We did a study to find out its benefits during vaginal hysterectomy.

Methods: It was a prospective case control study. Patients were divided into two groups. In the first group, no paracervical infiltration was given. In the second group paracervical infiltration was given before hysterectomy. The operating time, blood loss and postoperative infection were noted in each group.

Results: The operating time was slightly higher in vaginal hysterectomy group without infiltration $(\mathrm{p}=0.025)$ The operating time in laparoscopic assisted vaginal hysterectomy group was not significant $(\mathrm{p}=0.0296)$. There was significant difference in Hemoglobin after surgery in both groups ( $\mathrm{p}$ value 0.614 for vaginal hysterectomy and 0.173 for laparoscopic assisted vaginal hysterectomy). There was no case of infection in both groups.

Conclusions: From our study, we concluded that paracervical infiltration offers no distinctive advantage during vaginal hysterectomy or laparoscopic assisted vaginal hysterectomy.

Keywords: Laparoscopic assisted vaginal hysterectomy, Saline Adrenaline infiltration, Vaginal hysterectomy

\section{INTRODUCTION}

The use of non-descent vaginal hysterectomy and laparoscopic assisted vaginal hysterectomy is on the rise in clinical practice. Traditionally Aqua dissection using Saline Adrenaline infiltration is used to facilitate dissection in both non-descent vaginal hysterectomy and laparoscopic assisted vaginal hysterectomy. ${ }^{1}$

However, its use may cause may raise blood pressure or can theoretically reduce blood flow and predispose to infection. $^{2}$

We did a study to find out whether aqua dissection facilitates surgery in non-descent vaginal hysterectomy and laparoscopic assisted vaginal hysterectomy. The aim was of the study was to find out whether aqua dissection using saline adrenaline infiltration facilitates surgery.

\section{METHODS}

This study was conducted in the Department of Obstetrics and Gynaecology and it was a prospective case control study. Ethical committee clearance was obtained from Kasturba Hospital Manipal via IEC 100/2015. The study was done from November 2015 and Nov 2017. All patients who underwent the study had informed consent taken from them. A total of 32 patients participated in the study. Only patients with Uterus less than 12 weeks underwent the study. A detailed history was taken. A thorough general and local examination was done before surgery. A preoperative work up was done and 
preanaesthetic clearance was obtained before surgery. All patients underwent Ultrasound examination of the pelvis before surgery. Patients with history of smoking, hypertension, ischemic heart disease, elevated serum creatinine were excluded from the study. Saline adrenaline preparation was made after diluting 1 ampoule ( $0.0018 \mathrm{gm}$ of Adrenaline) in $400 \mathrm{ml}$ of saline.

About 100-200 $\mathrm{ml}$ of the solution was infiltrated submucosally in the cases pericervically. While in the controls no infiltration was given. Patients who underwent laparoscopic assisted hysterectomy only upper pedicles were ligated by laparoscopy. Uterine Artery, Uteroscral ligament and Cardinal ligament were ligated vaginally.

In patients who underwent non-descent vaginal hysterectomy all stumps were ligated and bipolar cautery was not used. The patients were followed up. Time taken for surgery, blood loss and incidence of postoperative infection were analysed in each group. Haemoglobin was done 24 hours after surgery.

\section{RESULTS}

A total of 32 patients entered the study.16 subjects underwent vaginal hysterectomy and 16 underwent laparoscopic assisted vaginal hysterectomy.

In the vaginal hysterectomy group 8 patients had saline infiltration and rest 8 had no infiltration. 16 subjects underwent laparoscopic assisted vaginal hysterectomy. Saline adrenaline infiltration was given in 8 subjects and rest 8 did not have any infiltration.

All vaginal Hysterectomies were non-descent vaginal hysterectomies. Only Uterus less than 12 weeks entered the study. There was no significant difference between operating time between the two groups in laparoscopic assisted vaginal hysterectomy. There was slight increase in the operating time in the vaginal hysterectomy group (Table 1).

Table 1: Operating time.

\begin{tabular}{|llll|}
\hline Type of surgery & \multicolumn{3}{|c|}{ Operating time (Mean) in minutes } \\
\hline & $\begin{array}{l}\text { Saline } \\
\text { adrenaline } \\
\text { group }(\mathbf{n}=8)\end{array}$ & $\begin{array}{l}\text { No } \\
\text { infiltration } \\
(\mathbf{n}=8)\end{array}$ & $\begin{array}{l}\mathbf{p} \\
\text { value }\end{array}$ \\
\hline $\begin{array}{l}\text { Vaginal } \\
\text { hysterectomy } \\
\text { (n=16) }\end{array}$ & $46 \pm 5.93$ & $55.0 \pm 6.45$ & 0.025 \\
\hline $\begin{array}{l}\text { Laparoscopic } \\
\text { assisted vaginal } \\
\text { hysterectomy } \\
(n=16)\end{array}$ & $48.12 \pm 3.72$ & $52.77 \pm 12.01$ & 0.296 \\
\hline
\end{tabular}

There was no excess bleeding in the group received no infiltration (Table 2). There was no significant fall in
Haemoglobin concentration on Day 1 after surgery. There was no post-operative infection in the study.

Table 2: Change in haemoglobin.

\begin{tabular}{|llll|}
\hline & \multicolumn{2}{|l|}{ Change in Haemoglobin (gm/dl) } \\
\hline & $\begin{array}{l}\text { Saline } \\
\text { adrenaline } \\
\text { group }(\mathbf{n}=8)\end{array}$ & $\begin{array}{l}\text { No } \\
\text { infiltration } \\
(\mathbf{n}=8)\end{array}$ & $\begin{array}{l}\mathbf{p} \\
\text { value }\end{array}$ \\
\hline $\begin{array}{l}\text { Vaginal } \\
\text { hysterectomy } \\
\text { (n=16) }\end{array}$ & $0.5 \pm 0.5$ & $0.5 \pm 0.6$ & 0.614 \\
\hline $\begin{array}{l}\text { Laparoscopic } \\
\text { assisted vaginal } \\
\text { hysterectomy } \\
\text { (n=16) }\end{array}$ & $0.63 \pm 0.84$ & $1.34 \pm 1.17$ & 0.173 \\
\hline
\end{tabular}

\section{DISCUSSION}

Traditionally adrenaline infiltration has been used in making non-descent vaginal hysterectomy easier. ${ }^{1}$ Its use however can be associated with hypertension or tachyarythymias when inadvertently injected intravenously. We did a study to find out the outcome of vaginal hysterectomy and laparoscopic assisted vaginal hysterectomy with and without any infiltration. Adrenaline infiltration can cause a rise in blood pressure, which can be dangerous in an elderly patient.

Adrenaline infiltration by temporally decreasing blood flow may predispose to infection. In our study, we did not find any difficulty in patients undergoing both nondescent vaginal hysterectomy and laparoscopic assisted vaginal hysterectomy without saline adrenaline infiltration. There was slight increase in operating time in the group who underwent vaginal hysterectomy with infiltration.

Though saline adrenaline infiltration is supposed to reduce bleeding during vaginal surgeries in our series, we found that the bleeding was not high in the group which did not receive infiltration. We could not find any other studies comparing vaginal Hysterectomy with and without saline adrenaline infiltration. Recently some studies have used Dilute Vassopression during vaginal hysterectomy. ${ }^{3}$

Most Gynecologists use Local infiltration before vaginal hysterectomy. In a survey conducted in UK 86 percent of Gynecologists uses infiltration before vaginal hysterectomy. ${ }^{4}$

Some evidence suggests that use of infiltration do not prevent visceral injuries during vaginal surgerie. ${ }^{5}$ Though it appears that hydro dissection facilitates tissue dissection, there is some evidence that hydro dissection to do not facilitate tissue dissection. ${ }^{6}$

The use of vasoactive agents may impair blood supply and cause infection during vaginal hysterectomy. ${ }^{2}$ The 
operating time was slightly increased in vaginal hysterectomy without infiltration group. However the operating time in laparoscopic assisted vaginal group showed no increase in time with or without infiltration. There was no significant difference in hemoglobin concentration between the two groups.

\section{CONCLUSION}

Use of Saline Adrenaline does not offer any advantage during vaginal or laparoscopic assisted vaginal hysterectomy.

\section{ACKNOWLEGMENTS}

The authors would like to thank for the help provided for this study by Dr. Pratap Kumar, Dr. Jyothi Shetty, Dr. Sapna V. Amin and Dr. Shripad Hebbar.

Funding: No funding sources Conflict of interest: None declared

Ethical approval: The study was approved by the Institutional Ethics Committee

\section{REFERENCES}

1. Nosan M, Novak F, Mazovec M The decrease of hemorrhages in vaginal hysterectomies through administration of adrenaline, octapressine, Gynaecology. 1968;165(1):21-30.

2. England GT, Randall HW, Graves WL Impairment of tissue defences by vasoconstrictors in vaginal hysterectomies. Obstet Gynecol. 1983;61(3):271-4.

3. Julian TM, Johnson GW, Gosewhr JA. Vasopressin as a chemical tourniquet during vaginal surgery. $\mathrm{J}$ Gynecol Surg. 1993;9:161-4.

4. Latthe P, Kadian S, Parsons M, Toozs-Hobson P. Survey of use of local infiltration and vasoconstrictor in vaginal surgery. Gynecol Surg. 2007;4:187-9.

5. Ghezzi F, Cromi A, Raio L, Bergamini V, Triacca P, Serati $\mathrm{M}$ et al. Influence of the type of anesthesia and hydrodissection on the complication rate after tension-free vaginal tape procedure. Eur J Obstet Gynecol Reprod Biol. 2005;118(1):96-100.

6. Caliskan K, Nursal TZ, Yildirim S, Moray G, Torer $\mathrm{N}$, Noyan T. Hydrodissection with adrenalinelidocaine-saline solution in laparoscopic cholecystectomy. Langenbecks Arch Surg. 2006;391(4):359-63.

Cite this article as: Nambiar JM, Yettinamani B, Pai MV. Evaluation of outcome following paracervical infiltration with or without saline and adrenaline during vaginal hysterectomy. Int J Reprod Contracept Obstet Gynecol 2017;6:1942-4. 